\title{
U-Slot Patch Antenna Using Space Reduction Optimization
}

\author{
P. Subramanian, P. Sujatha Therese
}

\begin{abstract}
Wireless communications has been created in the modern world particularly during micro-strip patch antenna. The future development of the individual Communication devices will expect to give images, speech and data information at any time. In this work, the structure and presentation of a co-axial feed $U$ slot micro-strip antenna for $24.7 \mathrm{GHz}$ WLAN application is obtainable. The return loss and VSWR of these proposed methods are studying and analysing to using Simulation Technology of patch to enhance the transformation of antenna. In this proposed method is higher impedance of space reduction optimisation. The impact of the use of different search space creation strategies used. The methods were exhibited for the design space reduction. Various tables, graphs showing these comparisons with detailed analysis have been included in this paper.
\end{abstract}

Keywords--- U-slot Antenna, Micro Strip Antenna, Space Reduction Optimization

\section{INTRODUCTION}

The structure and to design of u-slot micro-strip antenna has wireless applications. Now a day the communication system is based on wireless because of expensive is less and communication path is flexible and alternative. The proposed antenna based on space reduction optimisation. In this optimizations are not better than to always. And it's needed to search for all improving specific programs. This optimisation, reduced to space reduction and during the compilation of program [1]. The proposed micro-strip patch antenna has different shapes are includes, i.e., U, E, I and T etc. in the proposed antenna. In this paper, using DGS algorithm based different shapes and radiating patch. The process of antenna gain is $2.58 \mathrm{~dB}$, size of $65 \mathrm{~mm} * 62 \mathrm{~mm} * 105 \mathrm{~mm}$. Then impedance bandwidths are highly compared with another patch antenna. It has been good radiation, useful Bluetooth application range and wireless communication application. Advantages of microstrip antenna, low cost, light weight and low volume [2]. Micro-strip u-slot patch antenna is investigated on using concept of equivalent circuit. The effect of caused by base length, width of u-slot and arm length are investigated by parametric proposed method. It's used in variety of applications, i.e, satellite communication, biomedical services, mobile communication, aircraft and radar. The theoretical simulation results are presented in proposed method [3]. This paper presents Bluetooth application and wireless communication. Technology of Bluetooth becomes rapidly growing field of mobile phone charging, profile, interference and recognition. Industrial scientific and

\footnotetext{
Manuscript received September 16, 2019.

P. Subramanian, Research Scholar, Department of Electronics and Communication Engineering, Nooral Islam Centre for Higher Education, Kumaracoil. T.N, India.

P. Sujatha Therese, Professor, Department of Electrical and Electronics Engineering, Nooral Islam Centre for Higher Education, Kumaracoil. T.N, India.
}

medical method can be used in the proposed method. Ushape micro-strip antenna is designed to applicable for 2.4GHz. It's widely used to light weight and low profile and drawbacks are low gain and narrow bandwidth [4]. Microstrip patch antenna has designed with double band u-slot structure which using ground regulator. The gain has reaching 1.786 to $4.80 \mathrm{~dB}$ respectively and directivity of 6.50 to $6.6 \mathrm{dBi}$. Communication technology has been prominent point of u-slot structure due to low profile and minimum mismatch loss of 0 to 10 [5]. In this proposed two-stage optimization advance, the aim of space organising a global point of optimal region rapidly, and the optimization can be applied the global point of optimal accuracy. The advantages improve the efficiency and simulation and based equation of the proposed method [6]. In this paper simulate and design with operating frequency of $5.6 \mathrm{GHz}$ and design to patch antenna of single u-slot micro-strip. It has been reduce to rectangular patch size of antenna and improved the return loos of antenna and gain. It implements of transmit and receives the horizontal direction is known as Omni-direction [7]. Proposed method is 5G application and design of $u$-slot rectangular patch array. The present method can be used as 5G application of multiple inputs and multiple outputs. Antenna designed at $27 \mathrm{GHz}$ frequency and the time duration of $2 S$ [8]. This paper represents the Micro-strip patch antenna working on L band for satellite communication with $2.5 \mathrm{GHz}$ frequency. One of the main antenna type is micro-strip patch antenna, which has been widely and it's consists of two sides. One side is radiating path and the other side is ground path. The numerous advantages of low cast, light weight, small size and low profile [9]. The analysis has been conducted by presenting four semi-circular U-shaped slot structures dependent on a theoretical definition. The formulation is approved with the equivalent LC lumped parameters in charge of yielding the notched frequency. The LC equivalent notched frequency has been proposed by analysing the $\mathrm{C}$ and $\mathrm{L}$ proportional formula, and it has been approved with simulated and estimated results [10].

\section{STRUCTURE OF MICRO-STRIP PATCH ANTENNA}

In recent situation, Micro-strip patch antenna has the physical characteristics for using mobile phones, Bluetooth application networks and wireless local communication. Communication technology was highly speed joined and increasing the performance of mobile applications. 
Micro-strip patch antenna mostly used to microwave frequencies and fabricated using micro-strip techniques. Micro-strip patch antenna, have data transmission system of around $3 \%$ to $8 \%$ for utilized in antenna information systems. The theory of the micro-strip patch antenna may be developing the communication procedure for the U-slot micro-strip patch antenna. Numerous methods have been devising to increase the communication network of microstrip patch antennas.

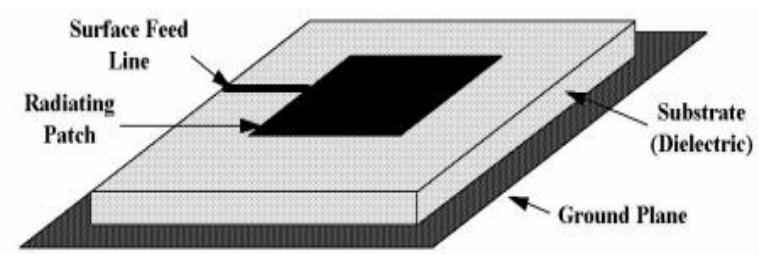

Fig. 1: Structure of Micro-Strip Patch Antenna

Two basic and common strategies are to expand the patch height or reduce the substrate permittivity. Two methods, the low-profile with realization, compact antenna component. And another method of achieving more extensive transmission system includes aperture coupled excitations yet this technique complicates the fabrication procedure because of the need for complex feed element design.

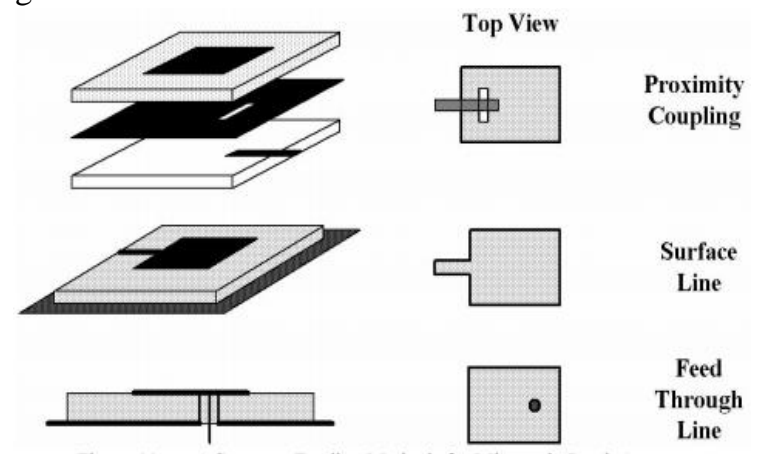

Fig. 2: Common Method for Micro-Strip Patch Antenna

This figure shows micro-strip u-slot patch antenna using micro-strip line feeding technique. In this planned antenna $\mathrm{u}$-slot patch is used to patch antenna section to $60 \Omega$ transmission system. This affects the input impedance and current flow of antenna. It is utilized in large variety of uses, for example, radar, rockets, aircraft, satellite communications, portable communication base stations, and handsets just as in biomedical telemetry administration.

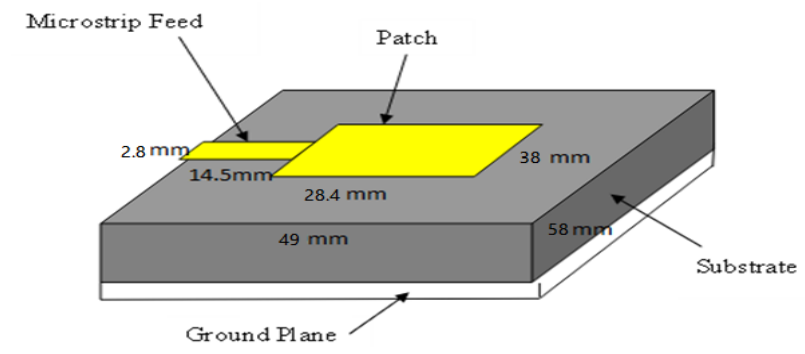

Fig. 3: Design of Micro-strip Patch Antenna

The varieties of U-slot patch antenna parameters for example, slot width, slot length, structure and patch size, test location and permittivity can change the receiving antenna's activities. The fundamental favourable circumstances of U-slot patch antenna are creates wide band attributes with single and easy topology. The impedance transfer speed for antenna is about $27.87 \%$ centred about $10.56 \mathrm{GHz}$.

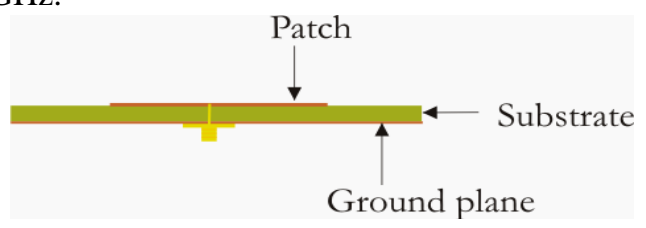

Fig. 4: Co-Axial Feed Technique

This feed technique is anything but difficult to create and low imitation of radiation. Recently, micro-strip patch antennas for various applications with coaxial-feed have been obtained Figure 4 show the co-axial feeding method. The internal conductor of the coaxial connector reaches from ground during the substrate and is welded to the radiating patch.

\section{FUNDAMENTAL PATCH ANTENNA DESIGN}

The basic design of patch antenna is explained in figure 5 which consists of radiating patch, substrate and ground.

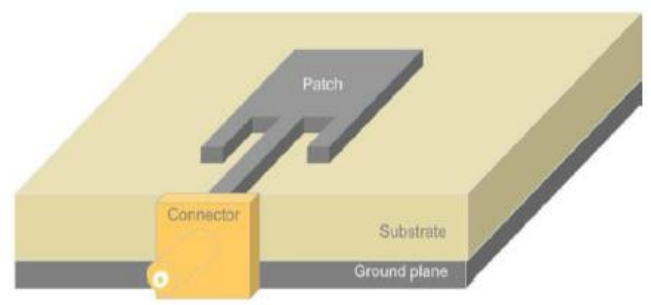

Fig. 5: Fundamental Design of Patch Antenna Width

Where $c$ is the free space of the speed $f_{o}$ is the frequency of resonant and $\mathbf{\varepsilon r}$ is the comparative substrate permittivity.

$$
\mathrm{W}=\frac{c}{2 f o \sqrt{\frac{(\varepsilon r+1)}{2}}}
$$

\section{Substrate}

Substrate assumes very important role of antenna routine parameters. During this moisture dealing with capabilities and commercially availability

$$
\begin{aligned}
& \text { Length } \\
& \qquad \begin{array}{l}
\mathrm{L}=\mathrm{L}(\mathrm{eff})-2 \Delta \mathrm{L} \\
\mathrm{L}(\mathrm{eff})=\frac{c}{2 f o \sqrt{(\varepsilon r e f f]}}
\end{array}
\end{aligned}
$$

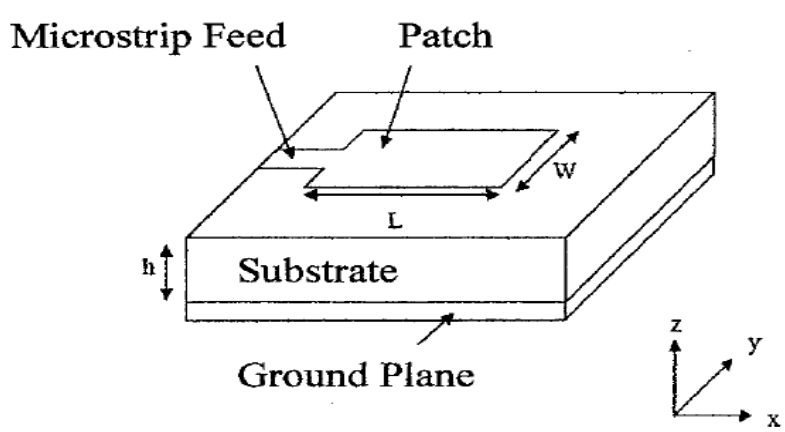

Fig. 6: Foundation of Micro-Strip Patch Antenna 
Micro-strip patch antenna is a simple antenna which consists of radiated patch component, ground plane, and the dielectric substrate. The radiated patch and ground plane usually is a thin layer of copper or gold which is a good conductor. This value is very important in the designing antenna and also has great influence to the size of the antenna.

Micro-strip antenna is a low profile antenna, planar and non-planar surfaces, easy and expensive to manufacture. It can increase the transfer speed and efficiency if the antenna, but unfortunately it will produce surface wave with low circulation that cause lot of intensity.

\section{Single U-slot Micro-Strip Patch Antenna}

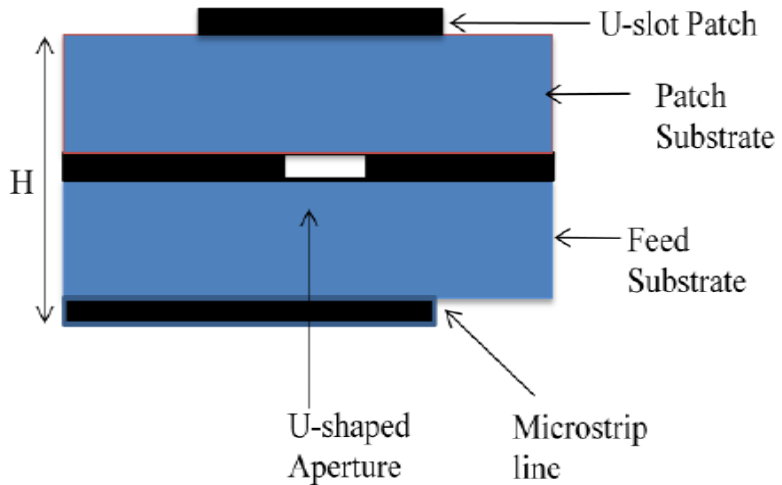

Fig. 7: Single U-slot Micro-strip Patch Antenna Design

Single U- slot patch antenna is shown in Fig7. Basically a simple opening joined micro-strip antenna coupled with rectangular patch, without some slot in it, results in single uslot antenna. However, when U-slot patch antenna is cut in the rectangular patch, and detailed within the matching antenna results in single u-slot operation.

\section{Dimensions for $u$-Slot Antenna}

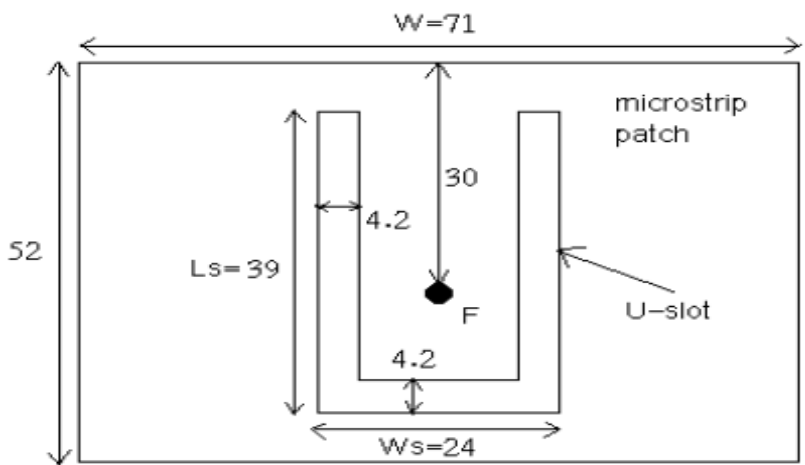

Fig. 8: Dimensions for u-slot Patch Antenna

In order to decrease the operating frequency to a centres frequency of $2.30 \mathrm{GHz}$, the feed probe has a diameter equal to $4.2 \mathrm{~mm}$. The probe of this antenna which has $4.2 \mathrm{~mm}$ diameter is thicker than the accessible probes. The simulation results of this antenna only with changing the probe diameter to $1.35 \mathrm{~mm}$ and maintenance other parameters are fixed.

\section{Mutual Coupling}

Mutual coupling is with firmly separated antenna design. Coupling might be radiation, from surface paths, from paths within the feed design or from reflections at the antenna terminal because of impedance mismatches.

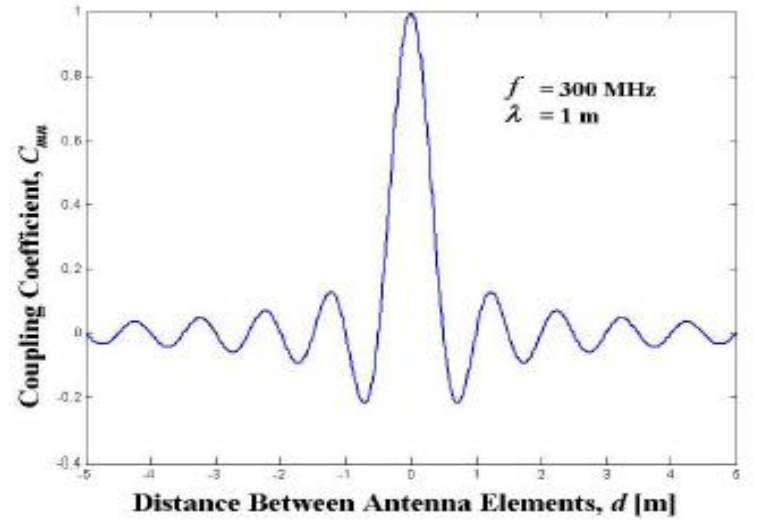

Figure 9: Distance between Antenna Elements, d[m]

Figure 9 graphs the connection between the common coupling coefficient and the division between antenna structures. Thus the impacts of mutual coupling are adulatory with the separation between the components with the envelope of the coupling coefficient reducing with separation.

$$
\mathrm{C}_{\mathrm{m}}=\sin \frac{k d_{m n}}{k d_{m n}}
$$

\section{Antenna Design and Configuration}

Design of patch antennas has based on incorporating slots or introducing multiple layers. Design of the proposed antenna is a combination of double U-slot and multilayer structure with air gap as one of the layer.

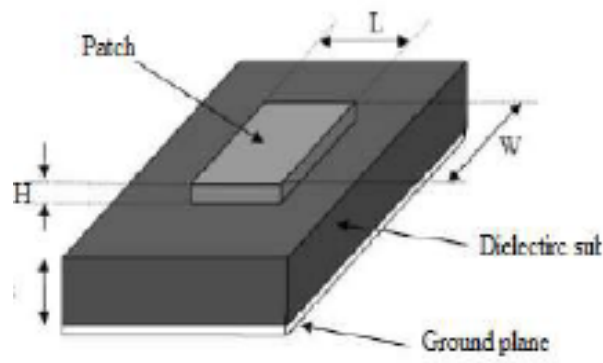

Fig. 10: Design of Patch Antenna

The constructional details of patch antenna are showing the figure 10. To design coaxial probe feed rectangular patch antenna, there are some essential parameters to be considered. Firstly, the resonant frequency f0 of the antenna should be selected appropriately. The dimensions for the micro-strip patch antenna are derived at the frequency of,

$$
\begin{aligned}
& f_{0}=\frac{c}{2 L \sqrt{\varepsilon_{\text {reff }}}} \\
& \mathrm{w}=\frac{c}{2 f 0 \sqrt{\frac{\varepsilon r+1}{2}}}
\end{aligned}
$$

Where,

$\varepsilon \mathrm{r}=$ dielectric constant

$\mathrm{c}=$ velocity of space

\section{SPACE REDUCTION OPTIMISATION}

Economic dispatch is the most significant issue as for respect to effective preparation of coordination planning and 
electric power system operation. Its main fundamental capacity is to decrease the cost of operation achieving different constraints in order to meet load demand. Generally cost of production in any power system is not deterministic as it changes instantaneously. In this economics production of electrical power from thermal energy needs optimum selection of units. The advanced method is more flexible and produced well balanced and improving to full fill the objective of this work.

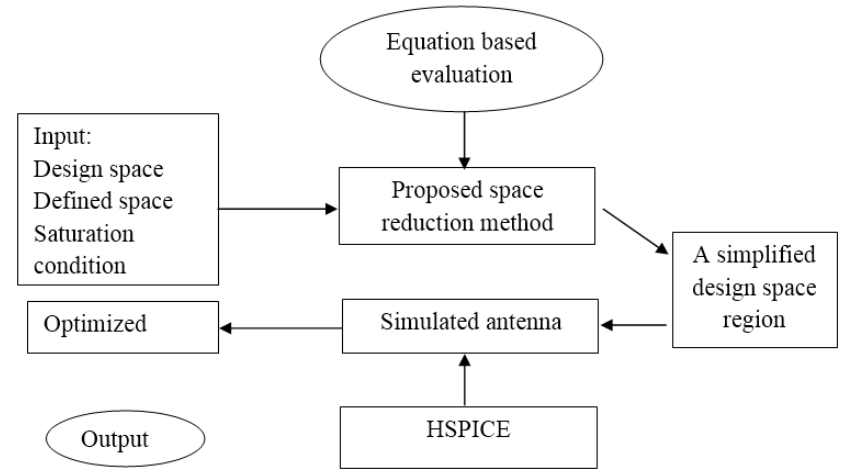

Figure 11: Basic of Space Reduction Optimization

Because of expanding of the complexity and measurement of space optimization effort in many applications, nowadays reduction issues are inverse that should show the system behaviour opening broad space reduction to the final optimum.

\subsection{Related Methods}

- Self-Organising Maps

- GK Cluster Algorithm

- Fuzzy C-mean method

- Partition Co-efficient

- Entropy Classification

- Partition Index

- Separation Index

- Xie and beni Index

\section{Self-Organising Maps}

One of the unsupervised neural systems is self-sorting map which is frequently utilized as an information mapping instrument. It can be utilized to linear statistical connections with dimensional information into simple connection of this image points of low-dimensional display and mean while keep up the original topological relations.

\section{Fuzzy C-mean Method}

Fuzzy C-Mean technique based algorithms are the most widely utilized fuzzy clustering algorithms by,

$$
\mathrm{J}(\mathrm{U}, \mathrm{W})=\sum_{j=1}^{g} \sum_{i=1}^{n}\left(\mu_{i j}\right)^{\mathrm{m}}\left\|X_{i}-V_{j}\right\|^{2}
$$

Where,

$$
\mu_{i j}=\frac{1}{\sum_{k=1}^{C}\left(\left\|X_{i}-V_{j}\right\| /\left\|X_{i}-V_{k}\right\|\right)^{2 / m-1}}
$$

\section{GK Cluster Algorithm}

GK stands by fuzzy c-means algorithm utilizing an adaptive in order to various geometrical shapes on information.

$$
\mathrm{J}(\mathrm{X}, \mathrm{U}, \mathrm{V})=\sum_{i=0}^{C} \sum_{j=1}^{n}\left(\mu_{i j}\right) \mathrm{m}\left\|X_{j}-V_{j}\right\|_{\mathrm{A}}^{2}
$$

Where,

$$
\begin{gathered}
D^{2}{ }_{i j}=\left(X_{j}-V_{i}\right)^{T} A_{i}\left(X_{j}-V_{i}\right) \\
\mathrm{D}^{2}{ }_{\mathrm{ij}}-\text { distance of square inner product }
\end{gathered}
$$

\section{Partition Co-Efficient}

It measures the amount of covering among clusters. It is characterized by,

$$
\mathrm{V}_{\mathrm{pc}}=\frac{1}{M} \sum_{i=0}^{c} \sum_{j=1}^{N} \mu_{i j}^{2}
$$

\section{Entropy Classification}

CE estimates the fuzziness of the cluster partition, which is like the Coefficient of Partition.

$$
\mathrm{V}_{\mathrm{ce}}=-\frac{1}{M} \sum_{i=1}^{c} \sum_{j=0}^{N} \mu_{i j} \log \mu_{i j}
$$

\section{Partition Index}

It is the proportion of the total of compactness and separation of the clusters.

$$
\mathrm{V}_{\mathrm{s}}=\frac{\sum_{i=0}^{c} \sum_{j=1}^{N} \mu_{i j}^{2}\left\|X_{i}-V_{i}\right\|}{N \min _{k i}\left\|V_{k}-V_{j}\right\|}
$$

\section{Separation Index}

In partition index, the division takes on a minimumdistance separation for partition power.

$$
\mathrm{V}_{\mathrm{S}}=\frac{\sum_{i=0}^{c} \sum_{j=1}^{N} \mu_{i j}^{2}\left\|X_{j}-V_{i}\right\|}{N \min _{k, i}\left\|V_{k}-V_{j}\right\|}
$$

Xie and Beni Index

$$
\mathrm{V}_{\mathrm{XB}}=\frac{\sum_{i=0}^{c} \sum_{j=1}^{N} \mu_{i j}^{m}\left\|X_{i}-V_{i}\right\|}{N \min _{j i \bar{i}}\left\|V_{i}-V_{j}\right\|}
$$

\section{Numerical Method}

The results gotten by direct PCA and the nonlinear techniques are exhibited in the subsequent subsections. Two assessment measurements are utilized to assess the technique performance about them.

\section{Evaluation Metrics}

The techniques are evaluated by the part of original geometric fluctuation resolved and the root mean square of matrix characterized as,

$$
\begin{gathered}
\beta=\frac{\frac{1}{2} \sum_{j=1}^{L} \sum_{k=1}^{s}\left(d_{k j}-\mu_{j}\right)}{2} \\
\text { RMSE }=\sqrt{\frac{1}{2}} \sum_{k=1}^{S}\left\|d_{k}-d_{k}^{2}\right\|
\end{gathered}
$$

\section{MULTI-OBJECTIVE OPTIMIZATION OF SPACE REDUCTION}

The least objective for each goal is once given by the organization. Cost of the product, performance ranges, and so on. How about we expect an objective for every goal is known in advance. The Vol space function, which is characterized the ranges of $\mathrm{x}$ component direction. At the point when the number of objects increments to the infinity, and two reduction design

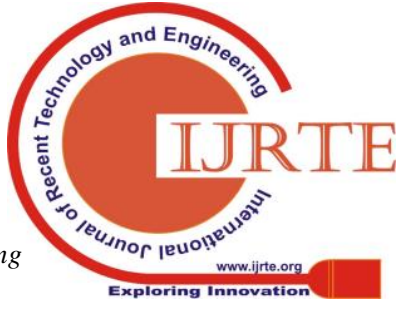




$$
\begin{aligned}
& \text { spaces } S_{a 1 \text { and }} S_{a(i+1)} \\
& \mathrm{C}=\lim _{i \rightarrow \infty} \frac{\operatorname{Vol}\left(S_{a 1} \cap S_{a(i+1)}\right)}{\operatorname{Vol}\left(S_{a 1} \cup S_{a(i+1)}\right)}=1
\end{aligned}
$$

Common Space Reduction Algorithm

$$
\begin{aligned}
& \text { Input: }{ }_{a}^{f 1} \text { and } S_{a}^{f 2} \\
& \text { Output: }_{a}^{f 1}, S_{a}^{f 2} \operatorname{Vol}\left(S_{a}^{f 2}\right)
\end{aligned}
$$

\section{Space Reduction Design of ANN Model}

In space reduction, which is one of the powerful and flexible technique is ANN's and bring exact output within presence of noisy input information.

Target from inputs are automatically predicts in machine learning technique in ANN's. It can be used in autonomous vehicles and research for reduction guide. The power of ANNs is representational express to variable interactions.

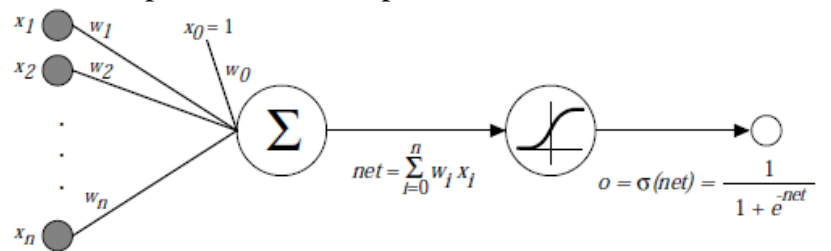

Figure 12: Activation Function of Space Design in ANN Method

Every unit operates on its contributions to create an output that it goes to the following layer. ANN's connected to feed-forward and each and every edges interface to each unit following next layer, conveying outputs to different units downstream.

A unit calculates it output by applying its foundation capacity to the weighted sum of all inputs are considered. Weights are introduced near zero, making the system to act like a direct model. As weights grow, the ANN becomes ever more nonlinear.

$$
\omega_{i_{i} j} \leftarrow \omega_{j_{,},} \eta \frac{\partial E}{\partial \omega_{j, i}}
$$

\section{Space Antenna Design}

The space antenna of an antenna is mainly controlled by the thickness, the nature of the dielectric substrate and the receiving antenna.

To expose the band width substance in basic structures and to give a benchmark as far as space and data transfer capacity, a rectangular patch has been measured. The components of the antenna can be concluded from scientific expressions.

$$
\begin{aligned}
& \text { Dielectric effective } \epsilon_{\text {reff }}=\frac{\epsilon_{r+1}}{2}+\frac{\epsilon_{r-1}}{2}\left[1+12 \frac{h}{W}\right]-{ }^{1 / 2} \\
& \text { Patch length } L=\frac{C}{2 f 0 \sqrt{\epsilon_{\text {reff }}}}-2 \Delta L
\end{aligned}
$$

Where, f0 = resonant frequency, ${ }^{\epsilon_{r}}=$ Dielectric constant

\section{RESULT}

The patch antenna is etched on a thin dielectric substrate with a thickness of $1.57 \mathrm{~mm}$. In order to increase the frequency, directivity, gain and bandwidth U-slot micro- strip antenna operating in various optimization techniques are used. In this Space Reduction Particle Swarm Optimization is applied to get better results.

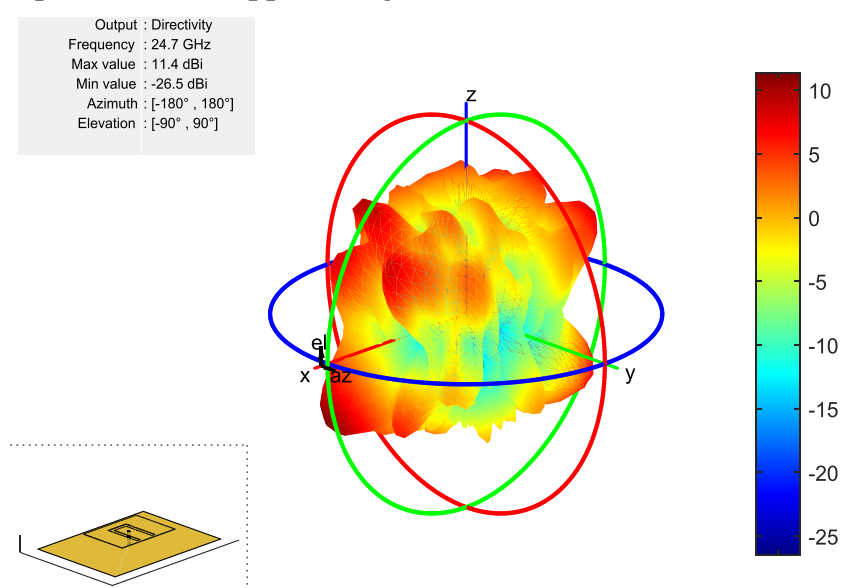

Fig. 13: Radiation Pattern of U-slot Antenna Using SRPSO

Simulated results shows that the radiation pattern at $24.7 \mathrm{GHz}$ of single U-slot micro-strip patch antenna using Space Reduction Particle Swarm Optimization with Directivity 10.5dBi in Figure.13.

The radiation pattern of an antenna gives the information about the energy radiation of an antenna.

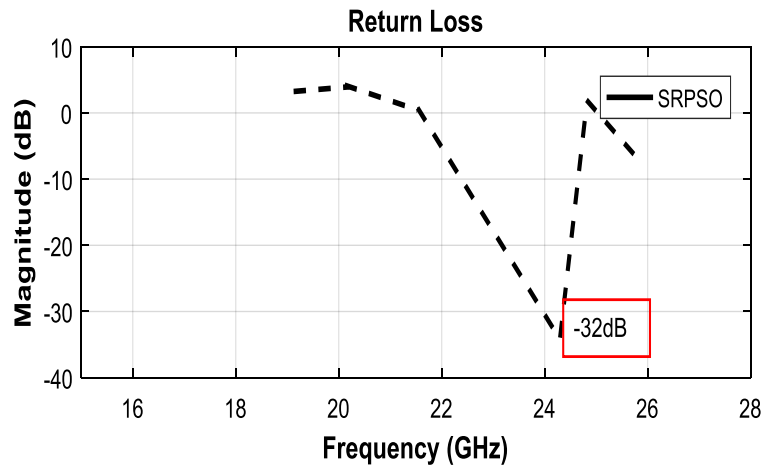

Fig. 14: Return Loss of the Antenna Using SRPSO

The Figure.14 shows the value of return loss in U-slot patch using Space Reduction Particle Swarm Optimization of an antenna is approximately-32dB.

VSWR

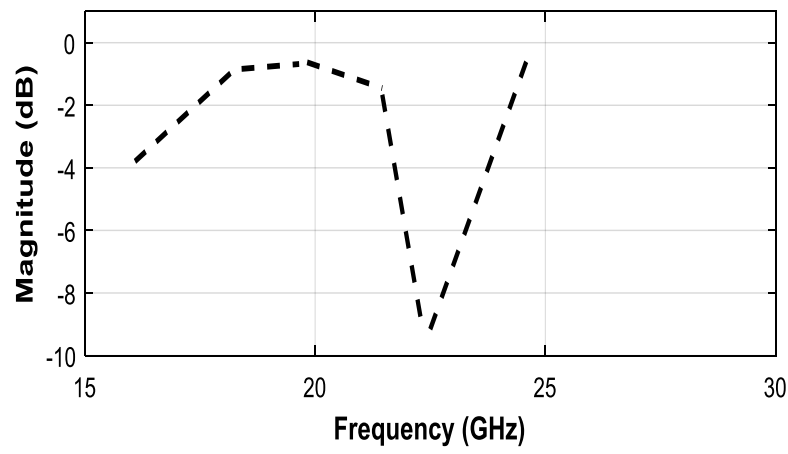

Fig. 15: VSWR of the Antenna Using SRPSO

Figure.15 shows that the input impedance of U-slot micro-strip patch antenna using Space Reduction Particle Swarm Optimization is matched properly. The antenna using SRPSO provides VSWR is 18.5.

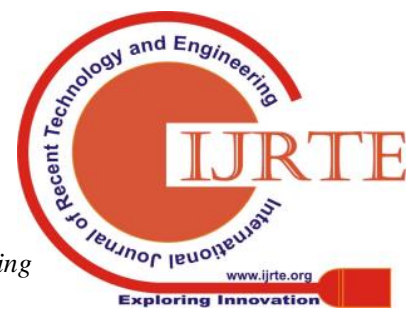




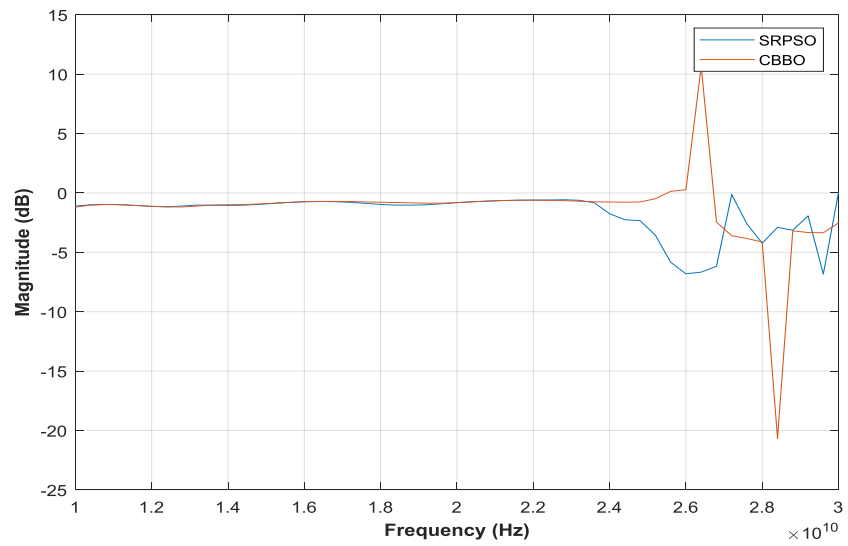

Fig. 16: S11 Plot of an Antenna Using SRPSO

Simulated result of antenna S11 parameter is compared with Space Reduction Particle Swarm Optimization of an antenna. The results shows that the simulated output of S11 using SRPSO gives better results when compared to the simulated output of shown in Fig.16.

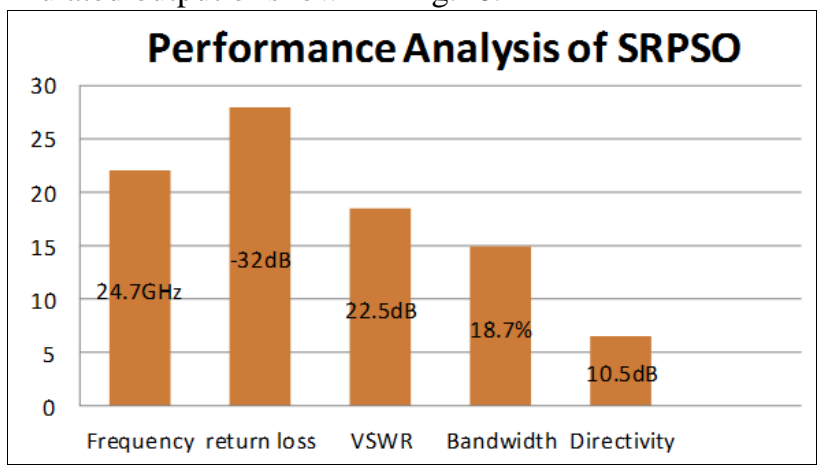

Fig. 17: Performance Analysis of an Antenna Using SRPSO

The performance analysis of SRPSO patch is compared with the parameters like Frequency, Return loss, VSWR, Bandwidth and Directivity. It resonates at $24.7 \mathrm{GHz}$ with a return loss of $-32 \mathrm{~dB}$. Directivity over $10.5 \mathrm{~dB}$ can be achieved in the frequency band from $22 \mathrm{GHz}$ to $28 \mathrm{GHz}$. The bandwidth improvement is $18.7 \%$ as shown in Figure.17.

\section{CONCLUSION}

In this paper a U-slot patch antenna with space reduction optimization have been presented. The proposed antenna can be considered to combination of u-slot patch antenna, which is used to fabricate. Our design provides space response of directivity, gain, steady radiation pattern and low return loss. The proposed antenna has been accepting W-LAN, and the other ratio services. It resonates at $24.7 \mathrm{GHz}$ with a return loss of $-32 \mathrm{~dB}$. Directivity over 10.5 $\mathrm{dB}$ can be achieved in the frequency band from $22 \mathrm{GHz}$ to $28 \mathrm{GHz}$.

\section{REFERENCES}

1. Garima, Amanpreet Kaur, Rajesh Khanna, and E. C. E. Student. "Dual-and Triple-Band U-slot Micro-strip Patch Antenna for WLAN Applications." International Journal of Advanced Research in computer and communication engineering, 2, (2013).

2. Ansari, Jamshed Aslam and Ram Brij Ram ""Broadband stacked U-slot microstrip patch antenna." Progress in Electromagnetics Research, 4 (2008).
3. Dong-You Choi, Jiwan and Ghimire, "Design of a Compact Ultra-wideband U-Shaped Slot Etched on a Circular Patch Antenna with Notch Band Characteristics for Ultrawideband Applications." International Journal of Antennas and Propagation (2019).

4. Changiz Ghobadi, Gh F, Khodae, and Javad Nourinia. "A practical miniaturized U-slot patch antenna with enhanced bandwidth." Progress in Electromagnetics Research (2008).

5. Saad Hassan, Kiani, Mehre Munir Khalid Mahmood, and Alex James Cole. "A Novel Design of Patch Antenna using U-Slot and Defected Ground Structure." international journal of advanced computer science and applications (2017).

6. Bahattin Türetken, Sürmeli and Koray. "U-slot patch antenna using high and low dielectric constant material combinations in S-band." In 2011 XXXth URSI General Assembly and Scientific Symposium, IEEE, 2011.

7. Ram Brij Ram and Ansari, J. A. "Analysis of broad band U-slot micro-strip patch antenna." microwave and optical technology letters (2008).

8. Danny, Andrea Serani, Emilio F. Campana, and Matteo Diez, D'Agostino. "Nonlinear methods for design-space dimensionality reduction in shape optimization." In International Workshop on Machine Learning, Big Data, Optimization, and pp. Springer, Cham, 2017.

9. Qiu, Haobo, Xiaoke Li, Liang Gao, Yanjiao Xu, and $\mathrm{Li}$ Chi. "Multi-stage design space reduction and metamodelling optimization method based on self-organizing maps and fuzzy clustering." Expert Systems with Applications (2016).

10. Emmerich, André H, Michael TM, and Deutz. "A tutorial on multi-objective optimization, fundamentals and evolutionary methods." Natural computing, (2018).

11. Jiang, Shengfeng Qin Jie, Guofu Ding, Yisheng Zou, and Jian Zhang. "A Systematic Optimization Design Method of Complex Mechatronic Products Design and Development." Mathematical Problems in Engineering 2018 (2018)

12. Mihir Narayan Mohanty, Sahoo, Laxmi Prasad Mishra, and Swarnaprava. "Optimization of Z-shape microstrip antenna with I-slot using discrete particle swarm optimization algorithm." Procedia Computer Science, 92 (2016). 